\title{
O PAPEL DO PROFESSOR NO ACOLHIMENTO ESCOLAR EM CASOS DE VIOLÊNCIA DOMÉSTICA COM OS ALUNOS
}

\author{
EL PAPEL DEL PROFESOR EN LA RECEPCIÓN ESCOLAR EN CASOS DE \\ VIOLENCIA DOMÉSTICA CON ESTUDIANTES
}

\section{THE ROLE OF THE TEACHER IN SCHOOL RECEPTION IN CASES OF DOMESTIC VIOLENCE WITH THE STUDENTS}

\author{
Rosangela Araújo dos SANTOS ${ }^{1}$ \\ Cristina SCHMIDT ${ }^{2}$ \\ Maíra Darido da CUNHA ${ }^{3}$
}

\begin{abstract}
RESUMO: A escola e o professor têm papel fundamental no acolhimento de alunos que passam por situações de violação a integridade de sua vida, em casos de agressões e abusos que possam ocorrer. Pesquisas revelam que a maior incidência de violência contra crianças e adolescentes geralmente acontece no ambiente familiar, acreditando ser uma forma de educar ou reproduzindo práticas sociais distorcidas. Por isso, os objetivos deste artigo são compreender o papel da escola e do professor no acolhimento da criança que sofre violação; levantar os índices de violência no município de Bertioga-SP; e, verificar se os professores percebem alteração no processo de ensino e aprendizagem dessa criança. $\mathrm{O}$ artigo foi realizado com levantamento bibliográfico e documental, e pesquisa de campo com professores de escolas de ensino fundamental I da região periférica e central da cidade, com o CREAS, e com o Conselho Tutelar de Bertioga - SP. Os dados coletados trouxeram elementos demonstrando que os professores entendem essa violência doméstica, constatando que essa situação interfere no desempenho escolar e, por isso, veem a escola como um dos locais fundamentais para o acolhimento da vítima, porém, nem todos têm o domínio dos procedimentos legais que amparam as crianças que sofrem violência.
\end{abstract}

PALAVRAS-CHAVE: Acolhimento escolar. Papel do professor. Violência doméstica.

RESUMEN: La escuela y el maestro desempeñan un papel fundamental en la acogida de los estudiantes que experimentan situaciones de violación de la integridad de sus vidas, en los casos de agresión y abuso que puedan ocurrir. Las investigaciones muestran que la mayor incidencia de violencia contra niños y adolescentes suele ocurrir en el entorno familiar, creyendo que es una forma de educar o reproducir prácticas sociales distorsionadas. Por lo tanto, los objetivos de este artículo son entender el papel de la escuela y el maestro en la recepción del niño que sufre violación; aumentar las tasas de violencia en el municipio de

${ }^{1}$ Faculdade Bertioga (FABE), Bertioga - SP - Brasil. Professora de Educação Básica da Prefeitura Municipal de Bertioga. Graduada em Pedagogia (FABE). ORCID: https://orcid.org/0000-0002-1461-1094. E-mail: rosangela.araujo@seducbertioga.com.br

${ }^{2}$ Faculdade Bertioga (FABE), Bertioga - SP - Brasil. Docente de Graduação e Pós-Graduação (UMC)/(FABE). Pós-Doutora (UNESCO/Metodista). Doutora em Comunicação e Semiótica (PUC-SP). ORCID: http://orcid.org/0000-0002-1208-2061.E-mail: crisschmidt@umc.br

${ }^{3}$ Faculdade Bertioga (FABE), Bertioga - SP - Brasil. Docente (FABE). Doutora em Educação Escolar (UNESP). ORCID: https://orcid.org/0000-0002-8263-882X. E-mail: maira_darido@yahoo.com.br 
Bertioga-SP; y verificar si los maestros perciben cambios en el proceso de enseñanza y aprendizaje de este niño. El artículo se llevó a cabo con encuesta bibliográfica y documental, e investigación de campo con profesores de escuelas primarias I en la región periférica y central de la ciudad, con CREAS, y con el Consejo Tutelar de Bertioga - SP. por lo tanto, ven la escuela como uno de los lugares fundamentales para la recepción de la víctima, sin embargo, no todo el mundo tiene el dominio de los procedimientos legales que apoyan a los niños que sufren violencia.

PALABRAS CLAVE: Recepción escolar. Papel del maestro. Violencia doméstica.

ABSTRACT: The school and the teacher play a fundamental role in welcoming students who experience situations of violation of the integrity of their lives, in cases of aggression and abuse that may occur. Research shows that the highest incidence of violence against children and adolescents often occurs in the family environment, believing it to be a way of educating or often reproducing what they also suffered. Therefore, the objectives of this article are to understand the role of the school and the teacher in caring for the child who suffers violation; raise the rates of violence in the city of Bertioga-SP; and, to verify if the teachers perceive alteration in the learning process of this child. The article was conducted with bibliographic and documentary survey, and field research with teachers in elementary schools 1 of the peripheral and central region, with CREAS, and with the Tutelary Council of Bertioga - SP. The data collected provided evidence that teachers understand this domestic violence and that school is one of the key places to receive the victim, but not all have the mastery of legal procedures that support children who suffer violence, but most admits that this situation interferes with school performance.

KEYWORDS: Domestic violence. Role of the teacher. School welcome.

\section{Introdução}

O índice de violência doméstica contra crianças e adolescentes têm aumentado, de acordo com pesquisas de IPSOS Violências Contra Crianças e Adolescentes-Percepções Públicas no Brasil (2017, p. 8), o Brasil fica em segundo lugar na América Latina no Índice de Risco de Violência Contra Crianças; considerado um país de alto risco de violência contra crianças. 
Figura 1 - Indicies de violência contra crianças e adolescentes na América do Sul

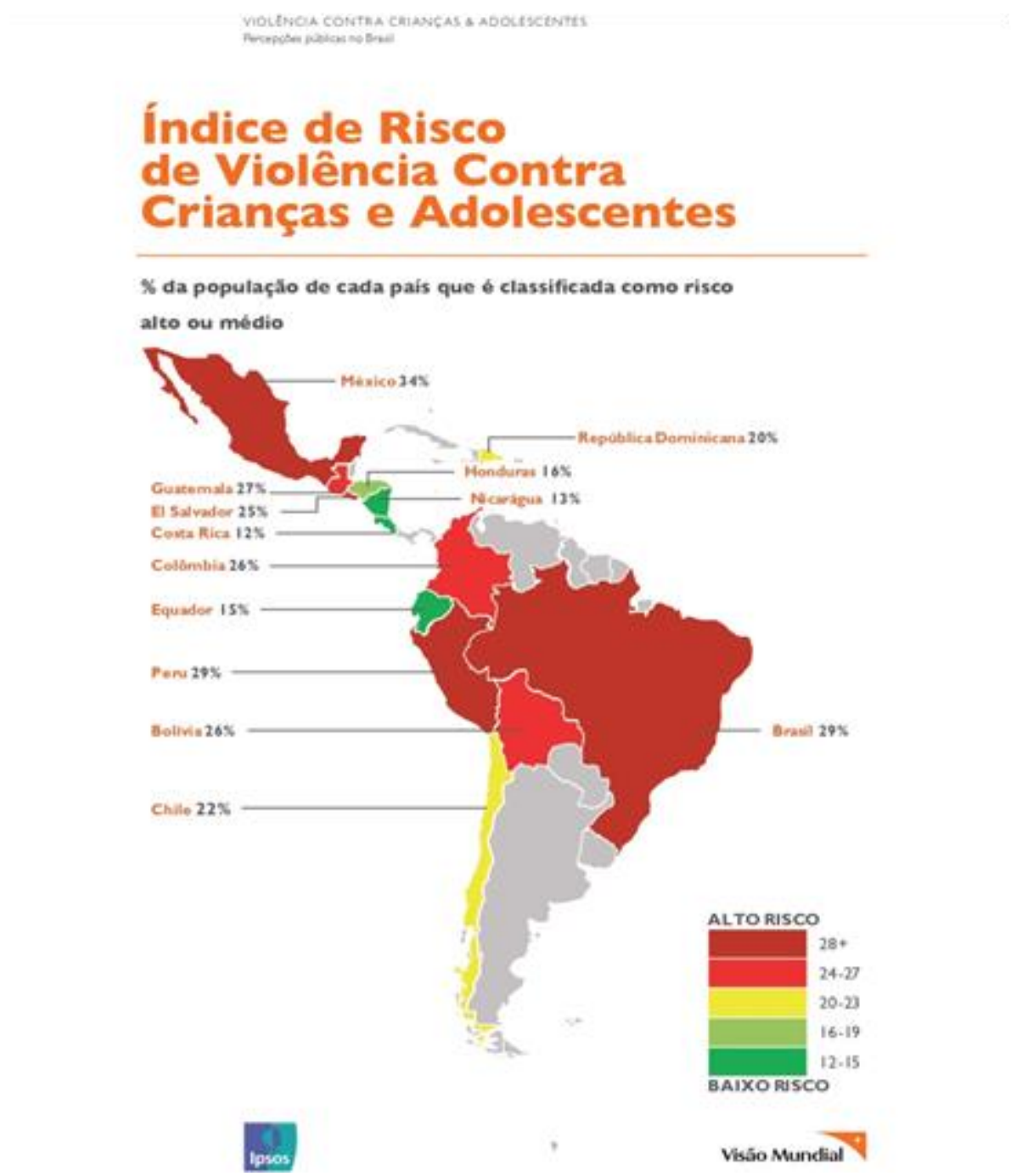

Fonte: IPSOS Violências Contra Crianças e Adolescentes-Percepções Públicas no Brasil (2017).

No município de Bertioga - SP, no ano de 2018, segundo dados do Conselho Tutelar, de acordo com o Mapa Estatístico de Ocorrências Atendidas, houve 5.926 denúncias de violências contra crianças e adolescentes atendidos pelos cinco Conselheiros Tutelares do município, que atenderam uma média de 100 casos por mês. Em 2019, no período de 01/04/2019 a 31/06/2019, houve 1.438 comunicações de violações de direitos contra crianças e adolescentes, contudo, no ano de 2018, no período de janeiro a março, houve 867 tipos de ocorrências atendidas de violências contra crianças e adolescentes.

A violência doméstica que as crianças sofrem pode ser: física, psicológica, verbal, de abandono ou sexual dentre outras que a mídia publica, nos faz pensar de que maneira podemos perceber no ambiente escolar como essas vítimas internalizam, como são as relações interpessoais e intrapessoais na escola, como isso reflete na aprendizagem. 
De acordo com Azevedo, a violência doméstica contra crianças e adolescentes:

[...] é uma violência interpessoal e intersubjetiva; - é um abuso do poder disciplinar e coercitivo dos pais ou responsáveis; - é um processo que pode se prolongar por meses e até anos; - é um processo de completa objetalização da vítima, reduzindo-a à condição de objeto de maus-tratos; - é uma forma de violação dos direitos essenciais da criança e do adolescente enquanto pessoas e, portanto, uma negação de valores humanos fundamentais como a vida, a liberdade, a segurança; - tem na família sua ecologia privilegiada. Como esta pertence à esfera do privado, a violência doméstica acaba se revestindo da tradicional característica de sigilo (apud MINISTÉRIO DA SAÚDE, 1997, p. $83)$.

De acordo com o ECA, é de responsabilidade do professor, caso haja indícios, a denúncia dos casos de violência e maus tratos contra criança e adolescente aos órgãos competentes, em caso de omissão, este pode sofrer sanções conforme legislação abaixo:

Art. 55. Os pais ou responsável têm a obrigação de matricular seus filhos ou pupilos na rede regular de ensino.

Art. 56. Os dirigentes de estabelecimentos de ensino fundamental comunicarão ao Conselho Tutelar os casos de:

I - Maus-tratos envolvendo seus alunos;

II - Reiteração de faltas injustificadas e de evasão escolar, esgotados os recursos escolares;

III - Elevados níveis de repetência (BRASIL, 1991)

As configurações de família dos tempos atuais têm sido modificadas, sofrendo mudanças devido à evolução da sociedade, já não sendo mais formadas por: pai, mãe e filhos biológicos. Em alguns casos têm sido compostas por casais homossexuais; bem como tem sido formada por avós ou parentes mais próximos, os quais assumem as responsabilidades, entre outras definições.

A família deveria ser um berço de proteção à criança e ao adolescente, o que muitas vezes não acontece; eles sofrem com a violência doméstica. Segundo pesquisa do IPSOS Violências Contra Crianças e Adolescentes-Percepções Públicas no Brasil (2017, p. 11), em 2015 houve registro de 42.085 violências domésticas contra crianças e adolescentes no Brasil. 
Figura 2 - Mito vs. Realidade \# 1

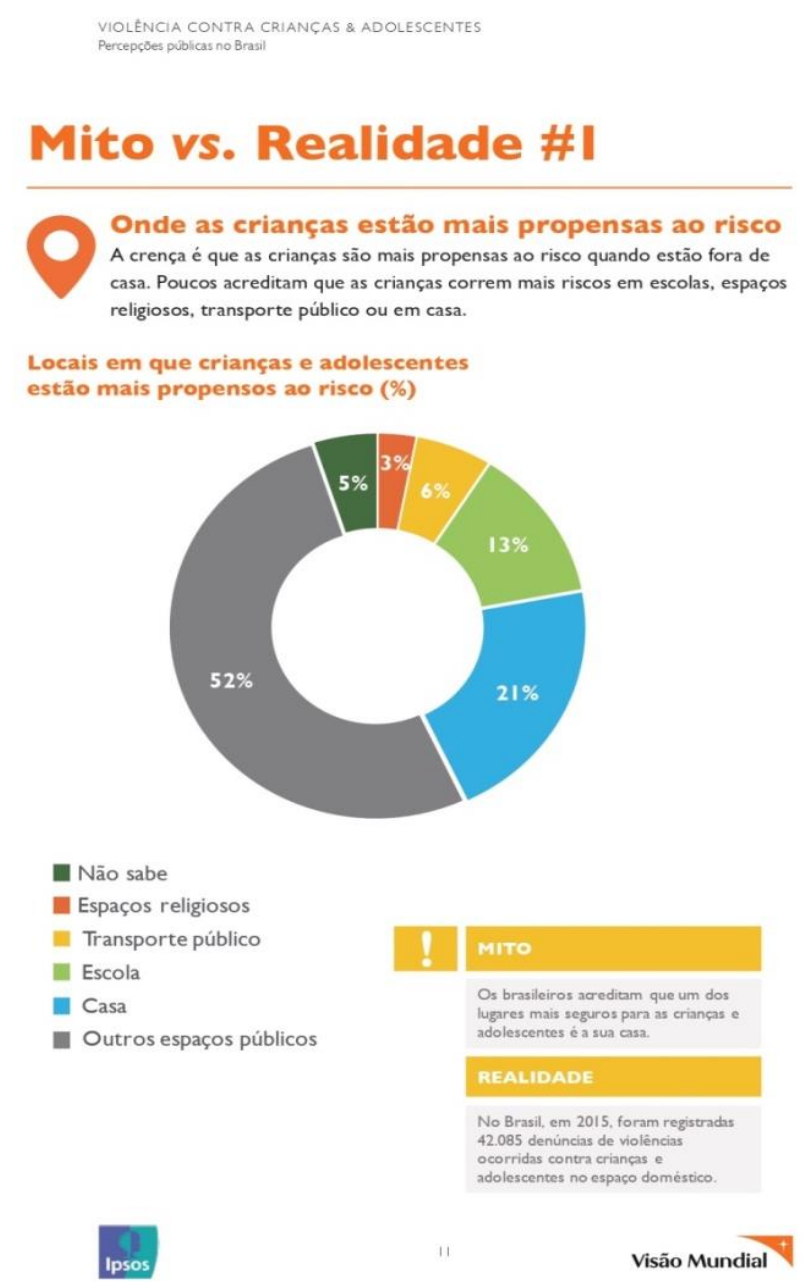

Fonte: IPSOS Violências Contra Crianças e Adolescentes-Percepções Públicas no Brasil (2017)

De acordo com o ECA - Lei no 8.069 de 13 de julho de 1990 em seu Art. 4º é dever da família, da comunidade, da sociedade em geral e do poder público assegurar, com absoluta prioridade, a efetivação dos direitos referentes à vida, à saúde, à alimentação, à educação, ao esporte, ao lazer, à profissionalização, à cultura, à dignidade, ao respeito, à liberdade e à convivência familiar e comunitária.

Nesse contexto, a família contraria o seu papel de proteção e segurança, ressaltando o sentimento de poder na prática da violência doméstica, tornando-se um problema público que envolve diferentes níveis sociais e instituições governamentais: saúde pública, segurança pública e violação dos direitos humanos, assistência social, educação. Nessa linha, tomando o aspecto educacional como um dos mais importantes segmentos para o enfrentamento dessa questão, o objetivo desse artigo está em discutir o acolhimento escolar da criança que passa por violência doméstica. E, para isso, entender os tipos de violência doméstica; levantar os índices de violência no CREAS e Conselho Tutelar em Bertioga - SP, apresentar quais os 
procedimentos legais da criança que sofre violência doméstica, levantar quais as recomendações legais e métodos pedagógicos para a escola adotar em caso de violação dos direitos das crianças e adolescentes, verificar como os professores entendem o acolhimento do aluno que sofre violência doméstica, averiguar se os professores percebem alteração no processo de ensino e aprendizagem dessa criança.

Para realizar essa reflexão, adotamos a abordagem qualitativa com método exploratório como linha condutora da pesquisa, considerando fundamentalmente os aspectos subjetivos do tema. A coleta de dados foi realizada por meio de levantamento bibliográfico, para a fundamentação teórica e documental, para obtenção de informações do CREAS e Conselho Tutelar. E, para complementar os dados da realidade local coletados em documentos, foi realizada pesquisa de campo em escolas públicas, situadas em diferentes bairros da cidade de Bertioga-SP, utilizando a técnica de entrevista estruturada com professores. Para a análise dos dados, o uso do método descritivo norteou a caracterização do objeto para as reflexões que se objetivaram.

\section{Características da violência doméstica}

Toda e qualquer violência praticada contra a criança e ao adolescente no ambiente familiar, cujos agressores tenham ou não laços de sangue com a vítima, causam grande transtorno físico e psicológico, eis que estas são as maiores vítimas dessas violências, pois são os mais vulneráveis e não têm como se defender,

Segundo Azevedo e Guerra (1995) a definição de violência doméstica:

Violência doméstica contra crianças e adolescentes é todo ato e/ou omissão praticado(s) por pais, parentes ou responsável em relação à criança e/ou adolescente que - sendo capaz de causar dor ou dano de natureza física, sexual e/ou psicológica à vítima - implica, de um lado, uma transgressão do poder/dever de proteção do adulto e, de outro, uma "coisificação" da infância, isto é, uma negação do direito que crianças e adolescentes têm de ser tratados como sujeitos e pessoas em condição peculiar de desenvolvimento (AZEVEDO; GUERRA, 1995, p. 36).

De acordo com a Proposta Preliminar de Prevenção e Assistência à Violência Doméstica (1997, p. 11-14) violência doméstica caracteriza-se como:

Violência física: toda e qualquer violência que agride fisicamente a criança ou o adolescente, deixando marcas no corpo como: queimaduras, socos, chutes, chineladas, fraturas 
e outras que muitas vezes não ficam apenas no físico, lesões que podem até levar a óbito a vítima.

Violência sexual: Para Azevedo e Guerra (1988, p. 05), esta violência configura-se como: "todo ato ou jogo sexual, relação heterossexual ou homossexual, entre um ou mais adultos e uma criança ou adolescente, tendo por finalidade estimular sexualmente esta criança ou adolescente ou utilizá-los para obter uma estimulação sexual sobre sua pessoa ou de outra pessoa".

Violência psicológica: Ocorre de maneiras diversas. Quando o adulto interfere censurando a criança ou adolescente, desabonando sua postura, suas habilidades, exigindo além das expectativas, depreciando todo e qualquer resultado obtido pela vítima.

Negligência: Ocorre quando o adulto responsável omite toda e qualquer necessidade: alimentos, saúde, vestuário, educação, proteção contra acidentes, abandono de incapaz.

Segundo Cardia (apud RISTUM, 1997, p. 32), uma pesquisa elaborada com alunos de três escolas públicas mostrou que "crianças que testemunham a violência dentro de casa, e que são agredidas pelos pais, tendem a ser agressivas e a ter comportamentos antissociais fora de casa, principalmente na escola".

Segundo Miller (apud LIMA; J. R., 2011). É notório o comportamento agressivo dessas crianças por viverem em situações de vulnerabilidade, elas reproduzem o comportamento agressivo que vivenciam no ambiente familiar.

A violência doméstica sempre existiu, e por muito tempo não era vista como um malefício para o aprendizado escolar da criança. Porém, com a consolidação dos governos democráticos e o reconhecimento cada vez maior dos direitos humanos, a maioria dos países ocidentais passou a formalizar políticas públicas de valorização da infância, dos direitos das crianças e dos adolescentes, a violência foi sendo enquadrada como crime e considerada um fator de risco para o aprendizado.

Os diferentes tipos de violência podem causar graves consequências, com diversos traumas psicológicos e físicos, sendo estes os que mais são observados depois de constatado a violência, e podem causar sérios traumas psíquicos, muitas vezes irreversíveis, com a possibilidade de eclodir para o caminho da delinquência.

[...] uma relação familiar conflituosa pode facilitar o envolvimento do adolescente com o uso de drogas que, por sua vez, estimula a entrada para o mundo infracional e também a associação entre a violência na comunidade, às condições econômicas da família, o possuir parentes presos por envolvimento na criminalidade e a utilização de drogas (ASSIS; SOUZA, 1999, p. 142).

Temas em Educ. e Saúde, Araraquara, v. 16, n. 1, p. 142-157, jan./jun., 2020. e-ISSN 2526-3471. 
Observamos em algumas escolas em que trabalhamos com reforço escolar no programa Novo Mais Educação, que contribuímos para que os alunos passem mais tempo na escola, afastando-os das ruas, melhorando o desempenho escolar. Ainda, como Agente de Apoio Escolar, auxiliando em atividades pedagógicas em sala de aula na educação inclusiva do ensino fundamental I, pudemos constatar que as crianças confiam no professor, no inspetor e em todos os funcionários que trabalham no ambiente escolar. Essa confiança se verifica, inclusive, que quando estão sofrendo algum tipo de violência desabafam com os profissionais da escola, na esperança de serem acolhidos, em busca de afeto e de soluções para suas aflições.

Segundo o artigo "O Acolhimento Institucional como Proteção a Adolescentes Vítimas de Violência: teoria ou prática?", as famílias agem como se a única solução para enfrentar os problemas fossem as agressões, como uma maneira de calar, frear o que eles não sabem resolver e ao invés de solucionar de uma maneira mais civilizada e coerente, diante do que para eles se apresenta como um problema a ser resolvido de maneira arcaica patriarcal.

Segundo Cardia (1997, p. 51), a violência doméstica aumenta a possibilidade do fracasso escolar e delinquência, e os jovens perdem o interesse de frequentar a escola.

\section{A escola que protege $\mathrm{e}$ o acolhimento}

De acordo com a Proposta Preliminar de Prevenção e Assistência à Violência Doméstica (1997 p. 19), é necessário incluir nos cursos de formação de educadores esta temática da violência contra crianças e adolescentes, e que seja incluído nos currículos escolares para que eles dialoguem com os educandos, e estes estejam conscientes de seus direitos, para uma precaução e identificação, na busca de combater esta adversidade.

Segundo o Jornal A Gazeta, de Vitória - ES (05/1973), no dia 18 de maio de 1973, na cidade de Vitória aconteceu um crime que ficou conhecido como "Caso Araceli”. Foi um crime bárbaro com uma menina de apenas 8 anos de idade que, após ser raptada, foi drogada, estuprada, morta e carbonizada. Essa violência brutal desdobrou em uma série de debates, e atos públicos. No ano de 2000, motivado por este caso e muitos outros, foi criado o Dia Nacional de Combate ao Abuso e à Exploração Sexual de Criança e Adolescentes.

A recomendação do Ministério da Educação, a partir dessa data, foi para que as escolas pautassem em suas atividades a temática da violência contra crianças e adolescentes que vem a cada ano aumentando os índices, com intuito de prevenção e conscientização desse problema. Além disso, fica explicitado no Estatuto da criança e do adolescente, ECA, em seu Art. 245 a 
responsabilidade civil de profissionais da educação e da saúde de comunicar casos de violações de direitos.

Art. 245. Deixar o médico, professor ou responsável por estabelecimento de atenção à saúde e de ensino fundamental, pré-escola ou creche, de comunicar à autoridade competente os casos de que tenha conhecimento, envolvendo suspeita ou confirmação de maus-tratos contra criança ou adolescente: Artigo 245 da Lei n 8.069 de 13 de julho de 1990. Pena - multa de três a vinte salários de referência, aplicando-se o dobro em caso de reincidência (BRASIL, 1991).

De acordo com o Estatuto da Criança e do Adolescente é de responsabilidade do professor fazer a denúncia ao Conselho Tutelar, e fazer o acolhimento da vítima no teor principalmente pedagógico, entendendo as suas dificuldades em relação ao aprendizado, socialização e mediando para que ele possa se sentir seguro.

\section{Pesquisa de campo}

Primeiramente, foi realizado um trabalho de levantamento documental em entidades que sistematizam dados relacionados com violência em geral e, especificamente, com violência doméstica do município de Bertioga-SP. Depois, seguimos com a realização de pesquisa em 03 escolas em região periférica e central, abrangendo um total de 37 professores de ensino fundamental I. Esses docentes foram inquiridos por meio da aplicação de questionário com 7 questões, sendo 4 dissertativas e 3 de múltipla escolha. A escolha das escolas foi realizada com base nos perfis socioculturais diferenciados, por isso, selecionadas em bairros diferentes da cidade de Bertioga: 13 são de bairros centrais, e 24 de bairros periféricos.

\section{Violência Doméstica em Bertioga}

Segundo informações do Conselho Tutelar do Município de Bertioga, as comunicações de Violações de Direitos por bairro correspondente entre 01/04/2019 a 31/06/2019, referem-se aos bairros com maiores índices de violações.

Os demais bairros apresentam entre zero a vinte e três casos, que somam um total de cento e oitenta e nove violações de direitos nos bairros não mencionados no quadro abaixo, perfazendo um total de mil cento e cinquenta comunicações de violações de direitos em Bertioga. 
Quadro 1 - Violações de Direitos em Bertioga

\begin{tabular}{|l|c|}
\hline DESCRIÇÃO & QUANTIDADE \\
\hline Chácara Vista Linda & 195 \\
\hline Jardim Rio da Praia & 164 \\
\hline Vicente de Carvalho II & 147 \\
\hline Centro & 121 \\
\hline Jardim Vista Linda & 102 \\
\hline Boracéia & 69 \\
\hline Jardim Indaiá & 67 \\
\hline Guaratuba & 54 \\
\hline Jardim Paulista & 42 \\
\hline Total & $\mathbf{9 6 1}$ \\
\hline
\end{tabular}

Fonte: Conselho Tutelar - Bertioga-SP

Segundo informações do CREAS do município de Bertioga-SP, essas violências contra crianças e adolescentes só são encaminhadas a este órgão quando os direitos da vítima foram violados, e eles realizam atendimentos a diversas violências contra os cidadãos de todas as idades, já o Conselho Tutelar é específico para atendimento a crianças e adolescentes somente, por esse motivo os índices do Conselho Tutelar são mais precisos.

Gráfico 1 - Registro de atendimentos do CREAS dos últimos anos

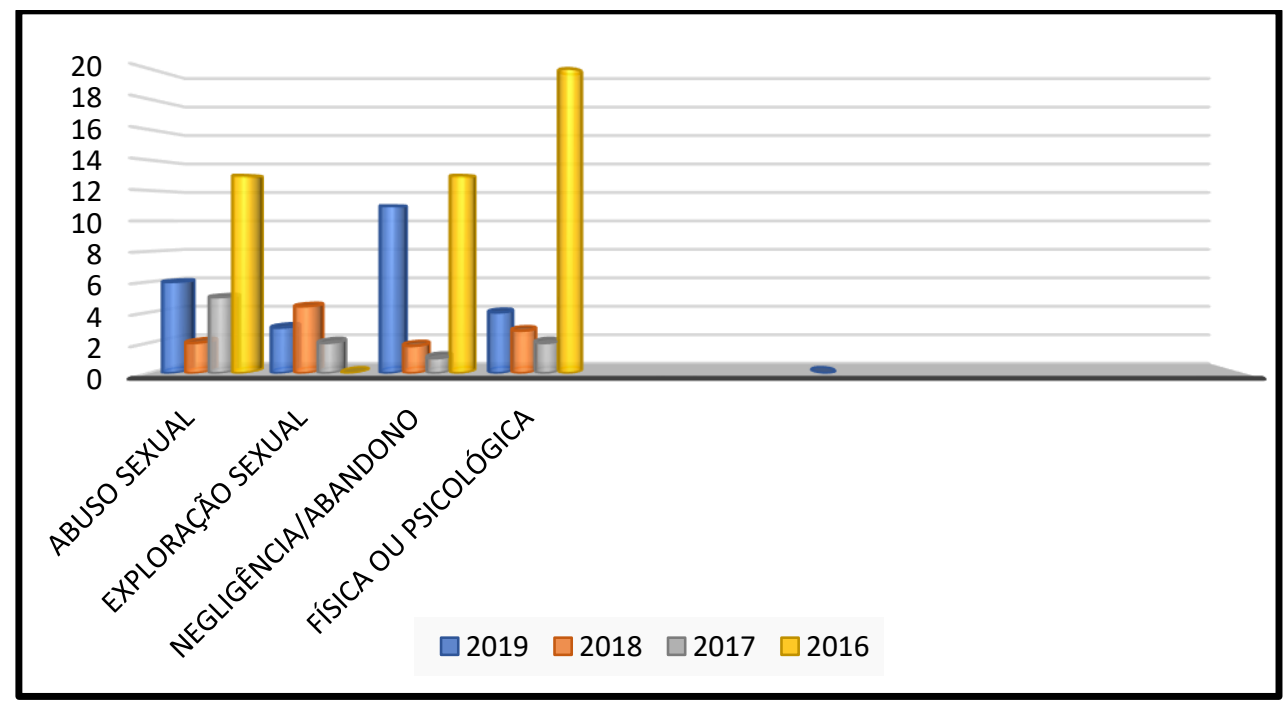

Fonte: elaborado pelos autores 


\section{Pesquisa de campo com professores Ensino Fundamental I}

Segundo Ipsos Reid-Violências Contra Crianças e Adolescentes-Percepções Públicas no Brasil, a violência contra crianças e adolescentes tem aumentado nos últimos anos, interfere negativamente na saúde, na educação infantil, nas relações interpessoais, na vida adulta. Conforme esse instituto, os aspectos psicológicos da criança e do adolescente que passa por uma violação de direitos ficam abalados no ambiente escolar, o desempenho cai e a indisciplina aumenta, e, sem motivação e acompanhamento escolar por parte dos pais, acentua o mau desempenho escolar.

Figura 3 - Impacto da Violência Contra Crianças e Adolescentes

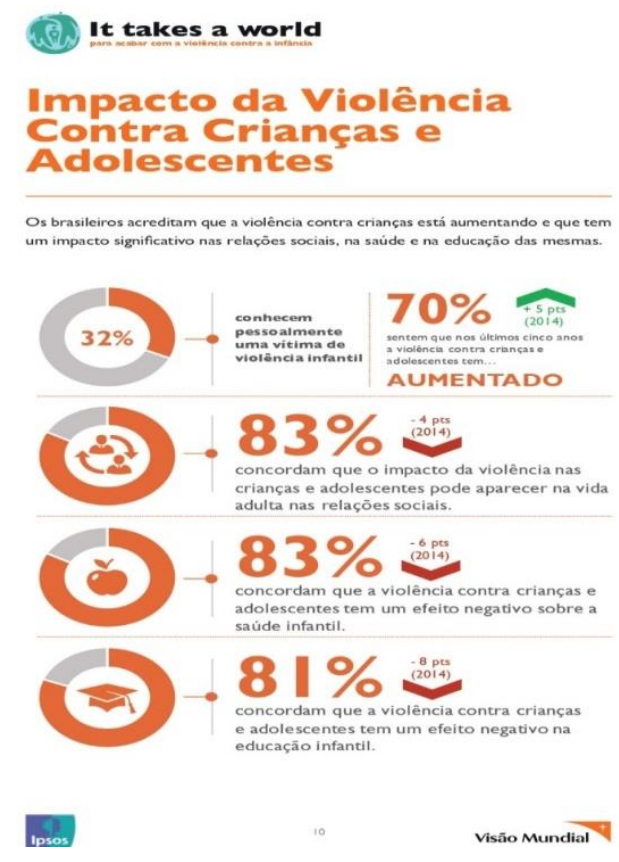

Fonte: IPSOS Violências Contra Crianças e Adolescentes-Percepções Públicas no Brasil (2017)

Nos gráficos que seguem abaixo, fica evidenciado o contexto escolar no tratamento da violação de direitos das crianças e adolescentes de Bertioga. No primeiro, estão mensurados os aspectos relacionados às questões: No item 1. Busca-se saber se o professor chega a conhecer casos de violência doméstica envolvendo alunos da sua escola. No item 2. A pergunta já procura a percepção do educador em relação à violência doméstica com seus alunos. Já no item 3. Busca-se verificar se o professor relaciona a violência doméstica sofrida com o desempenho escolar do aluno. E, no item 4, A questão procura averiguar se professor recebe algum curso ou treinamento para acolher crianças que sofrem violência doméstica. Para finalizar, no item 5 Tenta-se levantar o nível de preparação que o professor considera possuir para acolher na sala de aula as crianças vítimas de violência domésticas. 
Gráfico 2 - Professor e violência doméstica

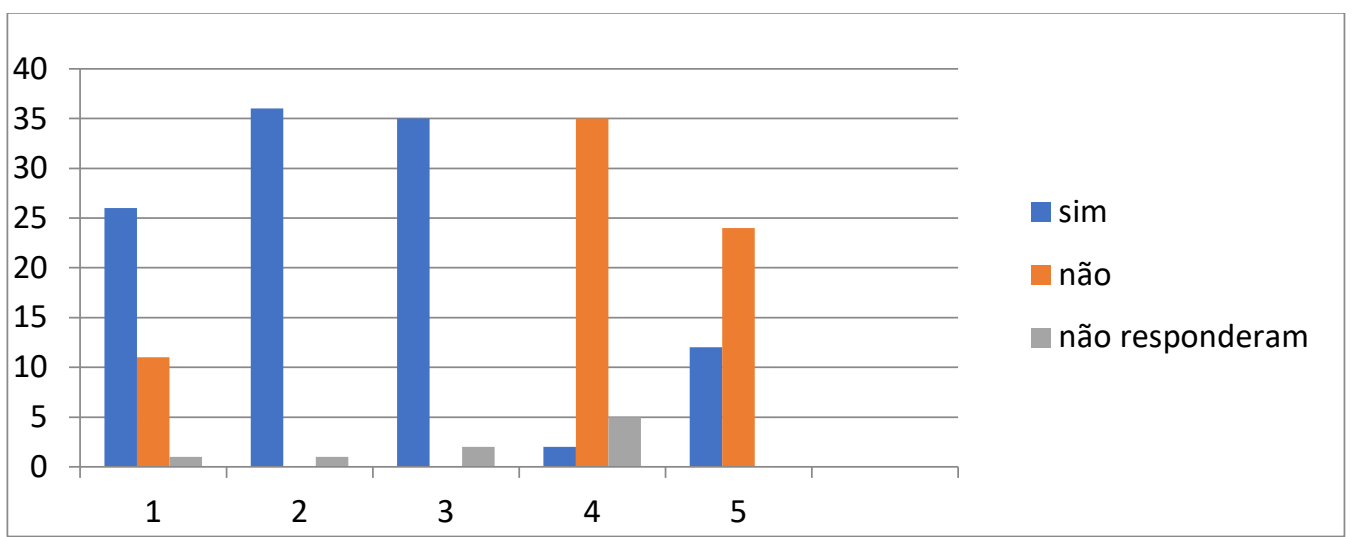

1 - Você conhece algum caso de violência doméstica envolvendo alunos da sua escola?

2 - Em sua opinião, o educador consegue perceber casos de violência doméstica?

3 - Existe relação entre violência doméstica e desempenho escolar?

4 - O professor recebe algum curso ou treinamento para acolher crianças que sofrem violência doméstica?

5 - Você se sente preparado para acolher na sala de aula as crianças vítimas de violência domésticas?

Fonte: elaborado pelos autores

Conforme o Gráfico 02, o professor consegue perceber e distinguir os tipos de violência que ocorrem com seus alunos. Também fica evidente, para eles, que essas situações prejudicam no processo de ensino e aprendizagem.

Segundo a pesquisa de campo, os docentes não recebem treinamento para acolhimento dos educandos vítimas de violências, e a omissão não deve ser opção em hipótese alguma, devese ter empatia, compreensão e carinho. Para acolhimento, não existem orientações referentes a possíveis condutas com o educando, ressaltam que são educadores que devem estar preparados para qualquer situação em sala de aula. Os educadores não tem nenhuma orientação de como lidar com casos de violências domésticas, é necessário dar atenção e amor para que a criança possa evoluir, e promover um ambiente mais acolhedor possível. 
Gráfico 3 - Tipos de violência domésticas recorrentes entre seus alunos

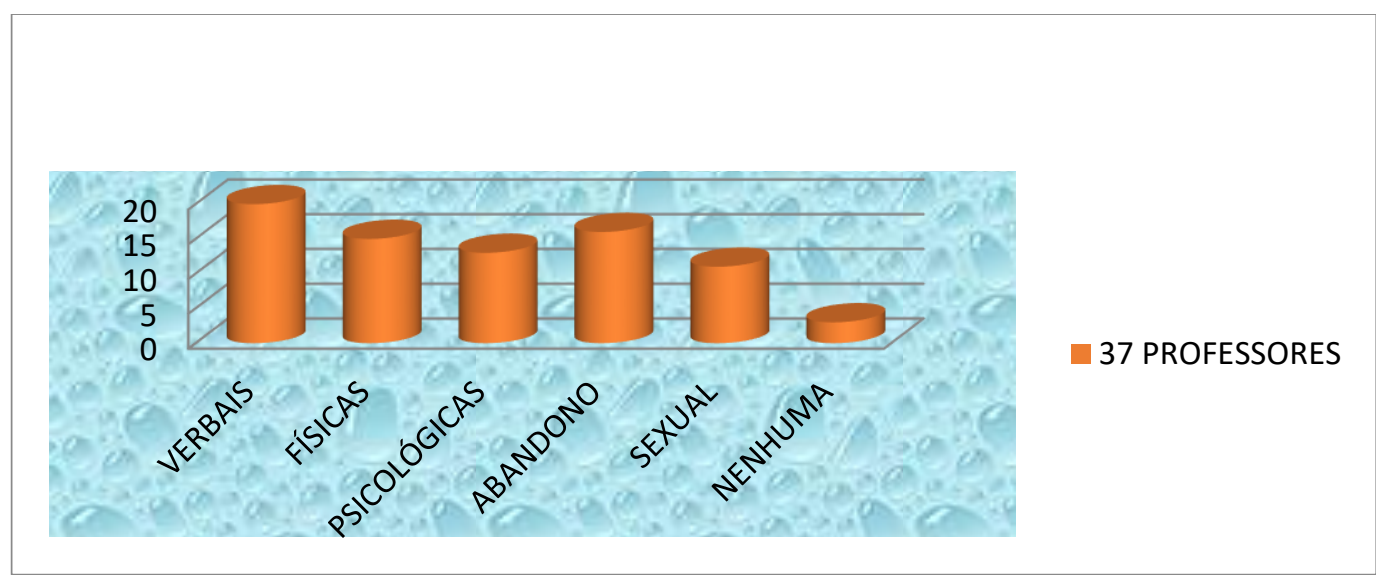

Fonte: elaborado pelos autores

De acordo com os professores entrevistados, do ensino fundamental I no município de Bertioga-SP, quando têm seus direitos violados, o educando acaba mudando o comportamento ou já tem um comportamento agressivo. Através da convivência, o educador conhece a conduta do educando e as transformações que ocorrem, conforme se verifica na lista apresentada abaixo, bem como através do artigo - Linha de Cuidado para Atenção Integral à Saúde de Crianças, Adolescentes e suas Famílias em Situação de Violências (BRASIL, 2010, p. 37), publicada pelo Ministério da Saúde: Aparência física; Muito quietos ou isolados; Não olhar nos olhos; Desenhos; Conversas e atitudes; Leitura sobre aspectos emocionais, cognitivos e físicos; Timidez, vergonha; Desmotivação para os estudos e apatia; Marcas no corpo; Jeito de se comunicar.

Sobre o desempenho escolar, o educando: recusa-se a participar das atividades; tem baixo rendimento e desenvolvimento escolar; não avança e, em alguns casos, regride. apresenta comportamento arredio ou violento a estímulos pedagógicos; perde a vontade de aprender e de se relacionar com os colegas.

A concentração e a socialização do mesmo são inadequadas, há um desequilíbrio emocional, falta de interesse com os estudos, dificuldades na aprendizagem que afetam o rendimento escolar, e o sentimento de impotência prejudica seu desempenho. 
Gráfico 04 - procedimento adotado pelo educador

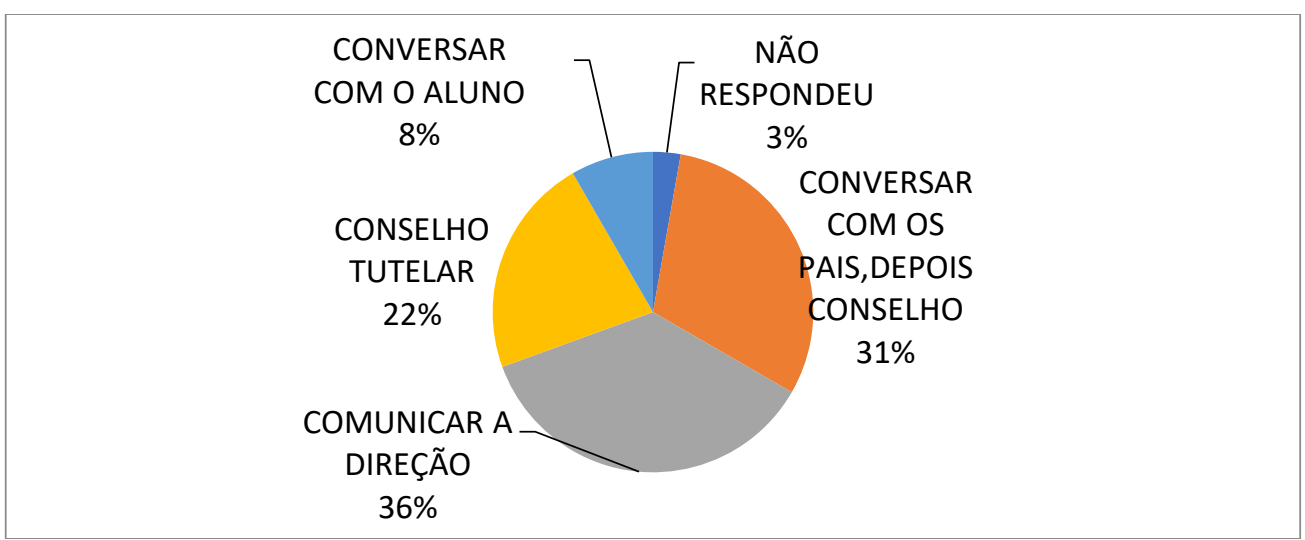

Fonte: elaborado pelos autores

A maioria dos professores relata que comunicam a direção os casos de violências domésticas, e posteriormente comunicam o Conselho Tutelar.

Um assunto delicado que requer seriedade e sensibilidade dos educadores e funcionários da escola em geral, pois os professores ficam doentes por falta de apoio e preparo psicológico, para que possam despertar a confiança e o afeto do aluno e amenizar seu sofrimento. Esta temática vai além da competência do professor, e é necessário o acolhimento da família por profissionais, tais como: psicólogos, assistentes sociais e mediadores de conflitos.

\section{Considerações finais}

Esta pesquisa constatou que a criança sofre diversos tipos de violência doméstica, e o educador e a escola têm papel fundamental no acolhimento de alunos que passam por situações de violações a integridade de suas vidas, pois os educadores percebem quando a criança está com problemas, e devem fazer a denúncia de maus tratos diretamente aos órgãos competentes, mas a grande maioria dos professores prefere comunicar a direção e, em seguida, conversar com os pais para depois fazer a denúncia no Conselho Tutelar.

Nas escolas onde ocorreu a pesquisa, muitos educadores revelaram que não estão preparados para fazer o acolhimento dos educandos por não terem nenhum treinamento, mas, procuram dar carinho e ter empatia, por tratar-se de um assunto delicado que deve ser acompanhado por psicólogos e assistentes sociais.

Foi realizada uma pesquisa de campo no município de Bertioga-SP com professores do ensino fundamental I, em região periférica e central, e constatou-se que a violência tem aumentado nos últimos anos, interferindo no processo de ensino e aprendizagem, socialização e concentração. 
A infância e a adolescência são períodos que precisam ser valorizados com ações de prevenção e cuidados contra todo tipo de violência, seja ela de qualquer tipo, eis que esta é uma fase que é determinante para a construção de valores.

Ocorre que a violência doméstica é uma violação de direitos que vem acontecendo há décadas, sendo necessário que se façam campanhas de prevenção contra esta temática.

A violência, principalmente a doméstica, segundo dados estatísticos, vem crescendo de forma abrupta, o que faz necessário ações de conscientização para evitar que estas crianças e adolescentes reproduzam tais violências sofridas, com a inclusão nas formações de professores métodos de acolhimento para as vítimas, e todos os funcionários do ambiente escolar possam ter orientações de acolhimento, pois a escola é um local onde geralmente essas violências são observadas e detectadas, além de o educando se sentir seguro para relatar os maus tratos ocorridos dentro e fora do ambiente familiar, sendo, claro, o educador que precisa estar preparado para fazer este acolhimento e denúncias aos órgãos competentes, de suspeitas de violências domésticas.

\section{REFERÊNCIAS}

BRANCO, M. A. O.; TOMANIK, E. A. Violência doméstica contra crianças e adolescentes: prevenção e enfrentamento. Psicologia \& Sociedade, v. 24, n. 2, p. 402-411. Disponível em: file:///C:/Users/rosan/OneDrive/Documentos/pedagogia\%208\%20semestres/violência\%20do méstica $\% 20$ contra $\% 20$ crianças $\% 20 \mathrm{e} \% 20$ adolescentes $\% 20$ prevenção $\% 20 \mathrm{e} \% 20$ enfrentamento. pdf Acesso em: 17 out 2019.

BRASIL. Estatuto da Criança e do Adolescente. Lei n. 8.069 de 13 de julho de 1990 em seu Art. 4º Brasília, DF: Ministério da Saúde, 1991.

BRASIL. Ministério da Saúde. Violência contra a criança e o adolescente: proposta preliminar de prevenção e assistência à violência doméstica. 1997. p. 19. Disponível em: http://lproweb.procempa.com.br/pmpa/prefpoa/sms/usu_doc/violencia_contra_a_crianca _e_o_adolescente.pdf. Acesso em: 08 out. 2019.

BRASIL. Ministério da Saúde. Linha de cuidado para atenção integral à saúde de crianças, adolescentes e suas famílias em situação de violências. 2010. p. 37. Disponível em: http://bvsms.saude.gov.br/bvs/publicacoes/linha_cuidado_criancas_familias_ violencias.pdf. Acesso em: 17 out. 2019.

CONSELHO FEDERAL DE PSICOLOGIA. Serviço de proteção social a crianças e adolescentes vítimas de violência, abuso e exploração sexual e suas famílias: referências para a atuação do psicólogo. Brasília, DF, 2009. Disponível em: https://site.cfp.org.br/wpcontent/uploads/2009/10/CREPOP_Servico_Exploracao_Sexual.pdf. Acesso em: 14 out. 2019. 
CONSIJ-PR CIJ-PR. Risco e violência: violência contra crianças e adolescentes. 2012. p. 18. Disponível em: http://www.crianca.mppr.mp.br/arquivos/File/publi/tj_pr/consij_ pr_risco_e_violencia_2012.pdf. Acesso em: 17 out. 2019.

LIMA, J. do R. A violência doméstica e a aprendizagem escolar. 2011. Disponível em: http://primeirainfancia.org.br/a-violencia-domestica-e-a-aprendizagem -escolar/. Acesso em: 17 out. 2019.

RISTUM, M. A violência doméstica contra crianças e as implicações da escola. Temas psicol., Ribeirão Preto, v. 18, n. 1, 2010. Disponível em:

org/scielo.php?script=sci_arttext\&pid=S1413-389X2010000100019. Acesso em: 14 out. 2019.

WORLD VISION INTERNATIONAL. Violências contra crianças e adolescentes: percepções públicas no Brasil, 2017. Disponível em: https://www.cenpec.org.br/wpcontent/uploads/2019/07/percepcao-brasileira-violencia-criancas-ipsos.pdf. Acesso em: 17 out. 2019.

\section{Como referenciar este artigo}

SANTOS, Rosangela Araújo; SCHMIDT, Cristina; CUNHA, Maira Darido. O papel do professor no acolhimento escolar em casos de violência doméstica com os alunos. Temas em Educ. e Saúde, Araraquara, v. 16, n. 1, p. 142-157, jan./jun., 2020. e-ISSN 2526-3471. DOI: https://doi.org/10.26673/tes.v16i1.13759

Submetido em: 05/01/2020

Revisões requeridas: 25/03/2020

Aprovado em: 08/05/2020

Publicado em: 19/06/2020 